\title{
Space probe set to size up polar ice
}

\section{Europe's ice-monitoring project gets a second chance after 2005 launch mishap.}

Almost five years after watching a launch failure destroy their ice-measuring satellite, Europe's polar researchers are ready to try again. For scientists hoping to understand how polar ice is reacting to climate change - and how sea levels may rise as a result - the stakes are higher than ever.

CryoSat-2, the satellite's second incarnation, is set to lift off on 8 April from a launch pad in Kazakhstan, aboard a converted Soviet missile. Technical problems with the rocket have already delayed the launch, which was originally scheduled for February. "I hope this time around probability is on our side," says Duncan Wingham, CryoSat-2's principal scientist, who will watch the launch from the

\section{"The coasts are where the action is and where we need the best data."}

on the thickness of glaciers and ice sheets just three days post-launch.

When CryoSat was first conceived more than a decade ago, its main objective was to determine whether Earth's large ice sheets were losing mass at all. Since then, measurements from other satellites have shown that the ice sheets on both Antarctica and Greenland are shrinking. But the error bars on the observations are high, and scientists cannot confidently forecast the future of the ice. Some forecasts, based on the relationship between temperature and sea-level changes during the twentieth century, suggest that the growing rate of ice loss could cause global sea levels to rise by 0.5-1.4 metres above those of European Space Operations Centre of the European Space Agency (ESA) in Darmstadt, Germany.

ESA's original mission to measure changes in ice sheets and sea ice in Earth's polar regions failed on 8 October 2005 when a software problem caused the commercial launch rocket to fail. By now, other satellites that monitor Earth's ice are either ageing or malfunctioning (see 'Keeping tabs on Earth's ice'). NASA's ICESat, for example, has lost the use of its key sensors, and stopped returning data last year; its successor will not be launched before 2015.

"CryoSat-2 gives us a new pair of eyes on what is happening to Earth's ice," says Robert Bindschadler, a glaciologist and chief scientist at NASA's Hydrospheric and Biospheric Sciences Laboratory in Greenbelt, Maryland. "The changes in the cryosphere are providing the most unequivocal evidence that we are changing our planet in ways that should concern us all."

\section{Centimetre accuracy}

After the loss of CryoSat, ESA's 18 member states decided, in 2006, to rebuild the $€ 135$-million (US\$182-million) satellite. The new probe is a copy of the original, but with redundancy in all of its critical instruments. Its main sensor is a sophisticated radar altimeter designed to measure the distance between the satellite and Earth's surface with such high precision that it will estimate ice thickness with an accuracy of a few centimetres. If everything goes according to plan, the radar will be turned on and will start to collect data
1990 by the end of this century (S. Rahmstorf Science 315, 368-370; 2007). But, rather than behaving like rivers, the coastal glaciers that drain the ice sheets may behave more like lines of traffic, starting and stopping. To make predictions, scientists need to understand how these glaciers behave and what governs their movements.

With the current limited sweep of observations, "our predictive ability is not very good", says Ian Howat, a glaciologist at Ohio State
University in Columbus, who studies the dynamics of ice sheets and their response to climate change. Because of their orbital orientations, current satellites can survey only around $10 \%$ of the coastal areas of Antarctica and Greenland. CryoSat-2 should help fill the gap. Reaching latitudes of $88^{\circ}$, it will provide a view of all the key coastal areas.

\section{Coastal retreat}

"The coasts are where the action is and where we need the best data," says Eric Rignot, an Earth scientist at the University of California, Irvine, who studies ice-sheet dynamics in Greenland and Antarctica. Getting a closer view of steep, narrow glacier channels along coastlines should help scientists to determine how glaciers respond to warmer temperatures.

The new information will ultimately feed into important policy decisions. Rising sea levels is one of the more manageable aspects of climate change because people can migrate away from coasts, says Bindschadler. "But the scientific information must be solid enough to justify policy decisions," he says, adding that, "CryoSat-2 data will play strongly in the science research that will predict future sea level."

\section{Quirin Schiermeier}

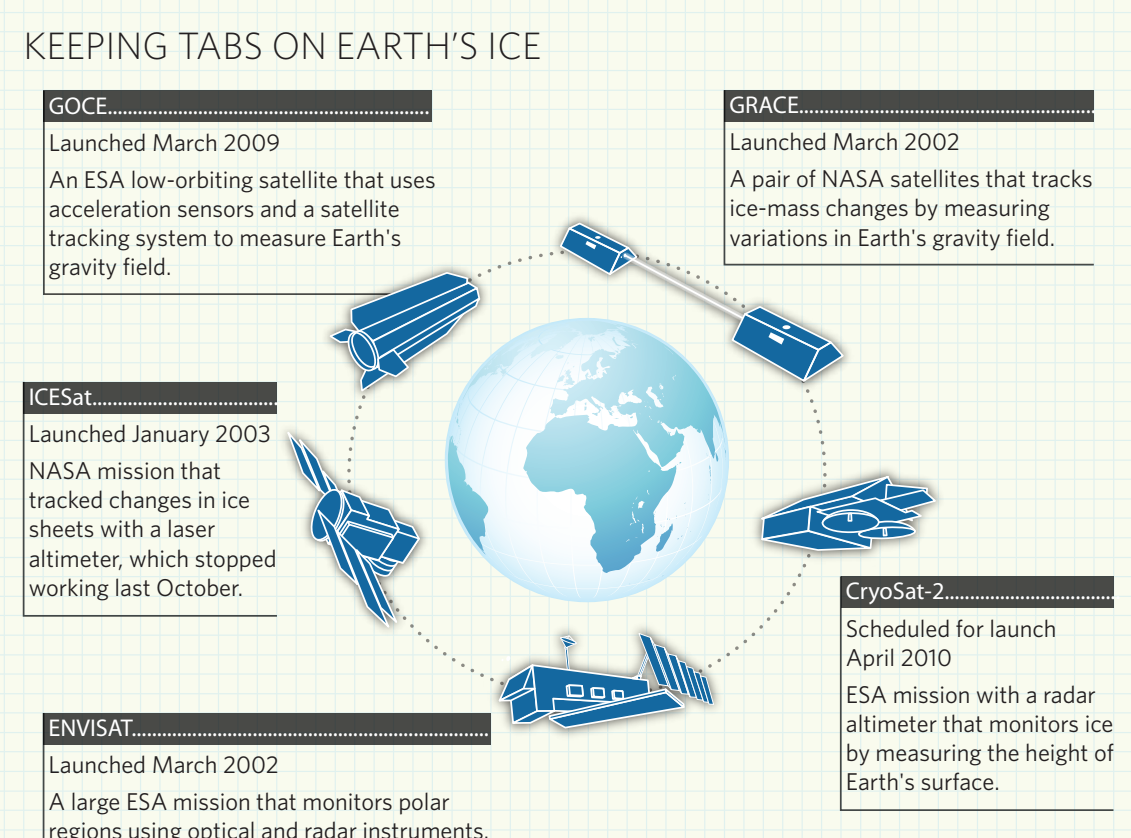

